\title{
A Review of Aluminum Alloy Fabricated by Different Processes of Wire Arc Additive Manufacturing
}

\author{
Zeli WANG, Yuanbin ZHANG*
}

School of Materials Science and Engineering, Shandong Jianzhu University, 1000 Fengming Load, Lingang Kaifa District, Jinan 250100, Shandong province, P.R.China

crossref http://dx.doi.org/10.5755/j02.ms.22772

Received 13 February 2019; accepted 06 May 2019

\begin{abstract}
Due to the advantages of high deposition rate, low equipment cost and high material utilization rate, aluminum alloy fabricated by wire arc additive manufacturing (WAAM) has been widely concerned by scholars and scientific institutions. This article reviews the features of aluminum alloy fabricated by different WAAM processes (GMAW-based, GTAWbased, CMT-based, PAW-based). Research status of the porosity, dimensional accuracy, microstructure and mechanical properties of aluminum alloy in different process is analyzed. General tendency of microstructure and mechanical properties were discussed, and suggestions for the future research direction were put forward including mandatory constraint on molten pool and structural topological optimization.
\end{abstract}

Keywords: WAAM, aluminum alloy, different processes, microstructure, mechanical properties.

\section{INTRODUCTION}

Additive Manufacturing (AM) refers to the technology of fabricating solid parts by layer-by-layer filling materials according to the path generated via computer controlled systems [1]. Compared with traditional manufacturing technology, AM has the advantages of low processing cost, short production cycle, high material utilization rate and diversified design. It has been widely concerned by scholars and research institutions since the 1980s [2, 3].

The heat sources used in AM includes laser, electron beam and arc [4], the filler materials are classified into powder and wire [5]. Wire Arc Additive Manufacturing (WAAM) is a technology that uses arc as a heat source to produce parts by continuously melting wire. The earliest application of the WAAM process dates back to 1925, Baker [6] used arc melting wire to deposite metal ornaments. Compared with other AM technologies, WAAM technology has the advantages of high deposition rate, simple equipment (normal welding equipment), large forming size and high material utilization rate [7]. WAAM can reduce the fabrication time of various engineering materials (such as titanium, aluminum, nickel and steel) by $40 \%-60 \%$, and the post-machining time could be reduced by $15 \%-20 \%$ [8]. At the present stage, substantial achievements have been made in WAAM research based on various engineering materials. Wang et al. [9] investigated the microstructure and mechanical properties of $\mathrm{H} 13$ mold steel thin-wall specimens that were fabricated using WAAM. Paul et al. [10] added slotted roller during WAAM of TC4 specimens to reduce the distortion and surface roughness. LIU Fen-cheng et al [11] obtained a $316 \mathrm{~L}$ stainless steel sample with a tensile strength of $605 \mathrm{MPa}$ and an elongation of $32.1 \%$ by WAAM.

\footnotetext{
* Corresponding author. Tel.: +86-138-54112137

E-mail address: zhang_yuanbin@163.com (Y.Zhang)
}

Aluminum alloy has low density, good plasticity, excellent thermal conductivity and good corrosion resistance, and it has been widely used in aerospace, transportation and other fields. [12,13] With the development of the science and technology, traditional casting and forging are difficult to achieve the manufacturing requirements of complex aluminum alloy components. [14, 15] AM has gradually become a reliable means of fabricating aluminum alloys, but not all AM processes are suitable for the production of aluminum alloys. Auminum alloy can reflect the laser, which leads to low laser absorption rate and slow forming speed. The electron beam needs a vacuum environment, which limits the formation of large parts $[6,16]$. Therefore, the WAAM for aluminum alloys has become one of the research hotspots. Wu et al. [8] summarized the performance, defects and quality improvement methods of aluminum alloys in WAAM. Derekar [6] reviewed how to reduce porosity, enhance tensile properties, and improve microstructure. Miao et al. [16] analyzed the current status and development prospects of aluminum alloy in the selection of laser melting, WAAM, laser-arc composite additive manufacturing.

Depending on the nature of the heat source, there are four types of WAAM processes: Gas Metal Arc Welding (GMAW)-based, Gas Tungsten Arc Welding (GTAW)based, Plasma Arc Welding (PAW)-based and Cold metal transfer (CMT)-based. As shown in Table 1 [8], different WAAM processes have various features. This article reviews the features of aluminum alloy fabricated by different WAAM processes (GMAW-based, GTAW-based, CMT-based, PAW-based). Through typical experiments, the research status of the porosity, dimensional accuracy, microstructure and mechanical properties of aluminum alloy in different WAAM processes is analyzed, the general 
tendency of microstructure and mechanical properties is discussed, and suggestions for the future research direction of aluminum alloy WAAM will be put forward.

Table 1. Features of different WAAM processes [8]

\begin{tabular}{|l|l|c|}
\hline \multicolumn{1}{|c|}{ WAAM } & \multicolumn{1}{|c|}{ Features } & $\begin{array}{c}\text { Deposition } \\
\text { rate, } \mathrm{kg} / \mathrm{h}\end{array}$ \\
\hline $\begin{array}{l}\text { GTAW- } \\
\text { based }\end{array}$ & $\begin{array}{l}\text { Non-consumable electrode } \\
\text { Separate wire feed process }\end{array}$ & $1-2$ \\
\hline $\begin{array}{l}\text { GMAW- } \\
\text { based }\end{array}$ & $\begin{array}{l}\text { Consumable wire electrode } \\
\text { Poor arc stability; spatter } \\
\text { Excellent spatial accessibility }\end{array}$ & $3-4$ \\
\hline $\begin{array}{l}\text { CMT- } \\
\text { based }\end{array}$ & $\begin{array}{l}\text { Reciprocating consumable } \\
\text { wire electrode } \\
\text { Low heat input; zero spatter }\end{array}$ & $2-3$ \\
\hline $\begin{array}{l}\text { PAW- } \\
\text { based }\end{array}$ & $\begin{array}{l}\text { Non-consumable electrode } \\
\text { Separate wire feed process } \\
\text { High energy density }\end{array}$ & $2-4$ \\
\hline
\end{tabular}

\section{WAAM PROCESS}

\subsection{GMAW-Based}

Gas metal arc welding (GMAW) is a process that utilizes arc formed between wire and weldment to melt wire with gas protection. According to the nature of the shielding gas, it can be divided into metal inert-gas welding (MIG) and metal active gas arc welding (MAG). Due to its advantages of low manufacturing cost, high production efficiency, and good spatial accessibility, it is regarded as one of the reliable WAAM processes [17-19].

GMAW-based can directly deposit aluminum alloy wire using welding equipment without external auxiliary apparatus, and the mechanical properties of formed parts are greatly different due to the content of alloying elements [20].Common aluminum alloys (ER1100, ER4043, ER4943, ER4047, and ER5356) were evaluated following GMAW-based by Amberlee et al. [21] The results shown the Al-Si alloys have the lowest porosity and highest strength, while the pure aluminum has low porosity and minimal compression ratio. The 5356 aluminum alloy has the highest porosity, resulting in a large difference in performance between WAAM specimens and forgings.

Because GMAW has large heat input, high deposition rate, and poor arc stability, the molten pool is easy to form overflow and collapsing in the combined effect of surface tension and arc blow force, which affects dimensional accuracy [22]. Moreover, the aluminum alloy has a high coefficient of thermal expansion, which is more prone to generating dimensional deviation and generate residual stress during filling process [8]. Zhao et al. [23] used GMAW with 5356 aluminum to analyze the influence of the GMAW-based processing parameters on the geometrical dimensions of the deposited layer. The width of the deposited layer increases linearly with the increase of the arc current, and the opposite trend occurs with the increase of the scanning speed. When the scanning speed is constant, as the number of deposited layers increases, the forming width increases slightly, and the height of each layer decreases slightly, as shown in Fig. 1 [23]. Fang et al. [24] proposed an adaptive process control scheme (APCS) to solve the issue of poor corner accuracy.

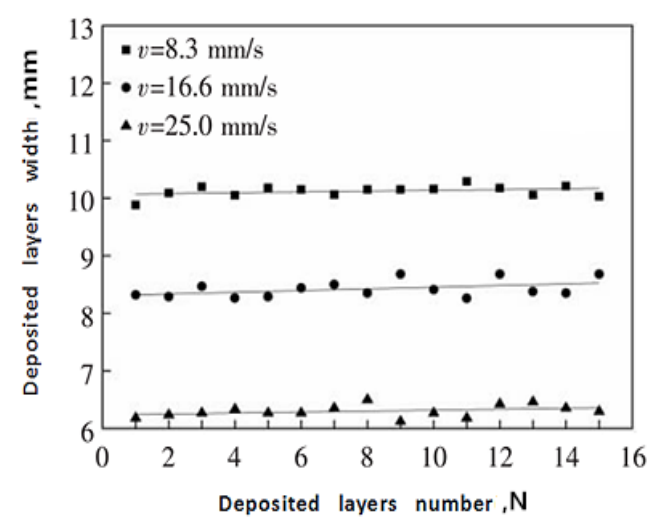

a

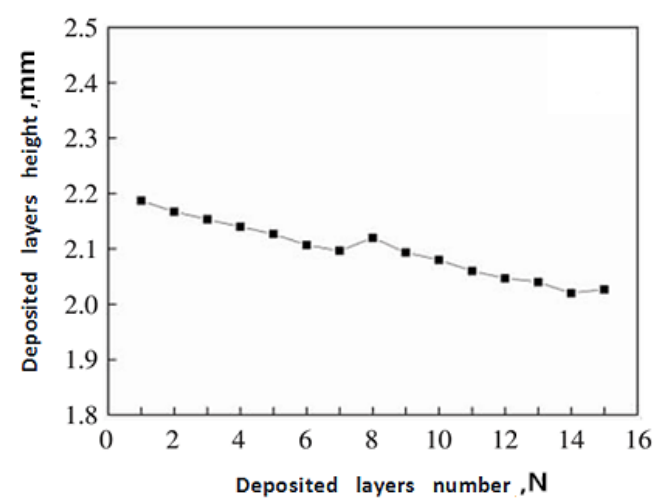

$\mathrm{b}$

Fig. 1. Influence of deposited layers number on dimensions parameters [23]: a-trend of deposited layers width; $\mathrm{b}$-trend of deposited layers height (Reproduced and adapted with permission from Ref. 23, Welding Editorial Department grants permission)

Experimental results show that the maximum dimension errors in the horizontal and vertical directions are reduced by $55 \%$ and $75 \%$ respectively. Luo et al. [25] used ER4303 aluminum wire to compare the difference between pulsed arc and non-pulsed arc in GMAW-based WAAM, which proves that using pulsed arc can reduce the droplet size while having high droplet transfer frequency.

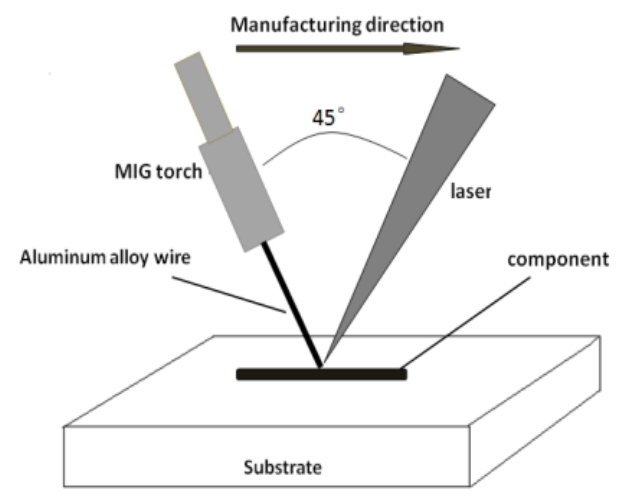

Fig. 2. Schematic diagram of WAAM with laser induction [26] (Reproduced and adapted with permission from Ref. 26, Welding Technology Editorial Department grants permission)

Sun et al. [26] proved that laser induction (as shown in Fig. 2) was added in the WAAM process, using laser to 
attract and compress the arc, the laser provides a stable spot for the arc, effectively suppressing arc jump and improve the dimensional accuracy of the aluminum alloy component.

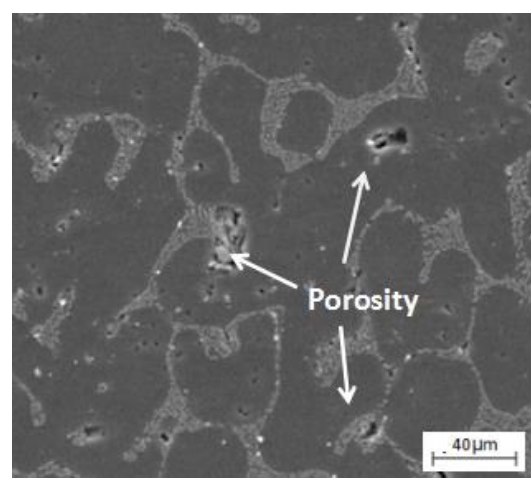

a

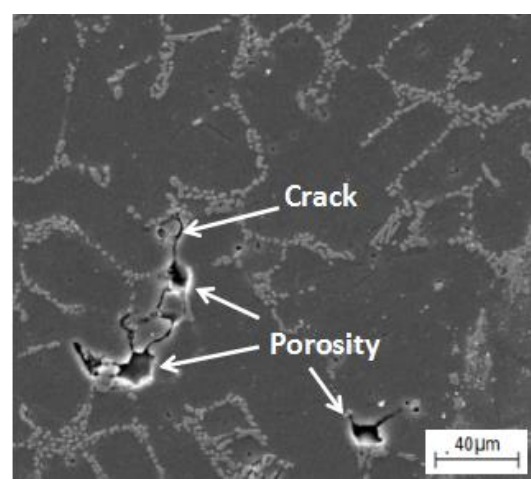

b

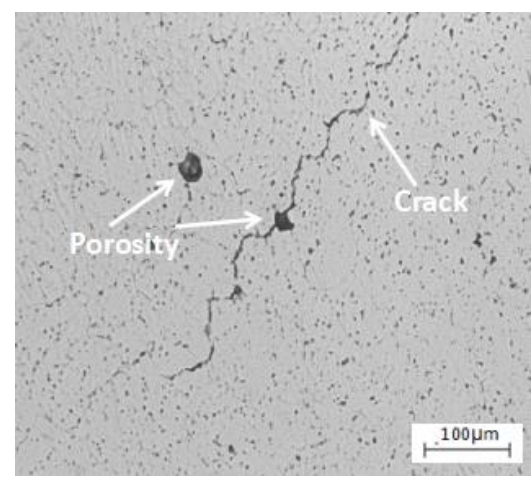

$\mathrm{c}$

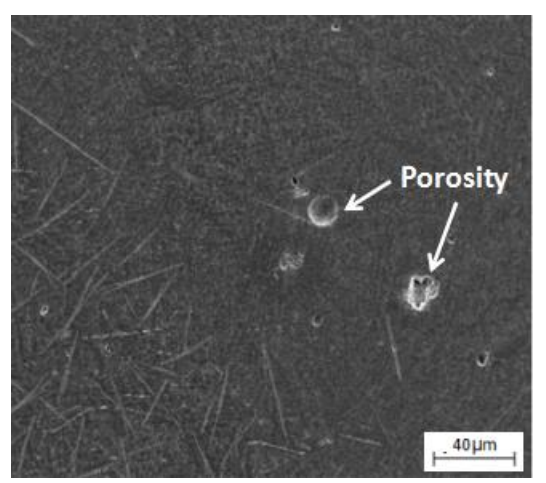

d

Fig. 3. Porosity and crack of different aluminum alloy: a-4043 aluminum alloy [21]; b-4943 aluminum alloy [21]; c-AA5183 aluminum alloy [32]; d - 4047 aluminum alloy [21] (Reproduced and adapted with permission from Ref. 21 and Ref. 32, Elsevier and Copyright Clearance Center grants permissions)
Porosity were found in the above experiments, which will weaken the strength of aluminum alloy and induce cracks (as shown in Fig. 3) [27, 28].

The main cause of porosity is that the solubility of hydrogen in aluminum alloy solids and liquids is $0.036 \mathrm{~cm}^{3} / 100 \mathrm{~g}$ and $0.69 \mathrm{~cm}^{3} / 100 \mathrm{~g}$ respectively [29]. Eliminating the source of hydrogen (such as wire drying and controlling the flow of shielding gas) is a common method of avoiding porosity and pulse arc have been proven to reduce the sensitivity of porosity $[25,30]$. In theory, when using double pulse arc (DP-GMAW) for WAAM, the arc size changes periodically with frequency, which destroy the coordination of pulse arc and increase the porosity trend. However, Celina et al. [31] used the DP-GMAW and Pulsed GMAW (P-GMAW) to fabricate 4043 aluminum alloy respectively. The results indicate that the DP-GMAW maintains the capability of porosity minimization.

\subsection{CMT-based}

CMT can be classified as one of GMAW according to the arc generation mode and wire feeding characteristics, but it differs from the conventional GMAW in that the CMT is digitally coordinated by the droplet transfer and the wire feeding motion. When The droplet touches the molten pool, the droplet transitions in the absence of current, thereby greatly reducing the heat input. [33,34] The process is suitable for the WAAM of low melting point metals such as aluminum alloy [35-37].

Compared with GMAW-based, CMT-based has lower transition temperature, and shorter gas escape time, which makes it more sensitive to generate porosity. Cong et al. [38] demonstrated that increasing the flow of pure argon (Shielding gas) in CMT-base WAAM can effectively reduce the porosity of aluminum alloy.

Cong et al. [37] studied the effects of four arc modes of conventional CMT, CMT pulse (CMT-P), CMT advanced (CMT-ADV) and CMT pulse advanced (CMT-PADV) on the porosity in the AA2219 aluminum alloy WAAM. The results shown conventional CMT is the most prone to generating porosity, and CMT-PADV is most beneficial for reducing porosity. In addition to eliminating the source of harmful gases and selecting the appropriate pulsed arc, inter-layer rolling process in CMT-based WAAM can reduce porosity of aluminum alloy [8].

$\mathrm{Gu}$ et al. [39,40] designed an inter-layer rolling equipment (as shown in Fig. 4) and used 2319 aluminum alloy wire and 5087 aluminum alloy wire to prove that the application of interlayer rolling process and interlayer heat treatment in CMT-base WAAM can greatly reduce the number of porosity. Bai et al [41] performed an overall heat treatment on CMT-based A2319 aluminum alloy, and the result illustrated that there are two related mechanisms in controlling the growth and the number increase of porosity after heat treatment. Which are the classical Ostwald Ripening effect and combination of hydrogen and vacancies effect, respectively. Although compared with GMAWbased WAAM, CMT-based has lower heat input and more precise arc length control, it still has higher deposition rate compared with other heat sources (laser, electron beam), which makes difficult to control the dimensional accuracy of aluminum alloy [16]. 


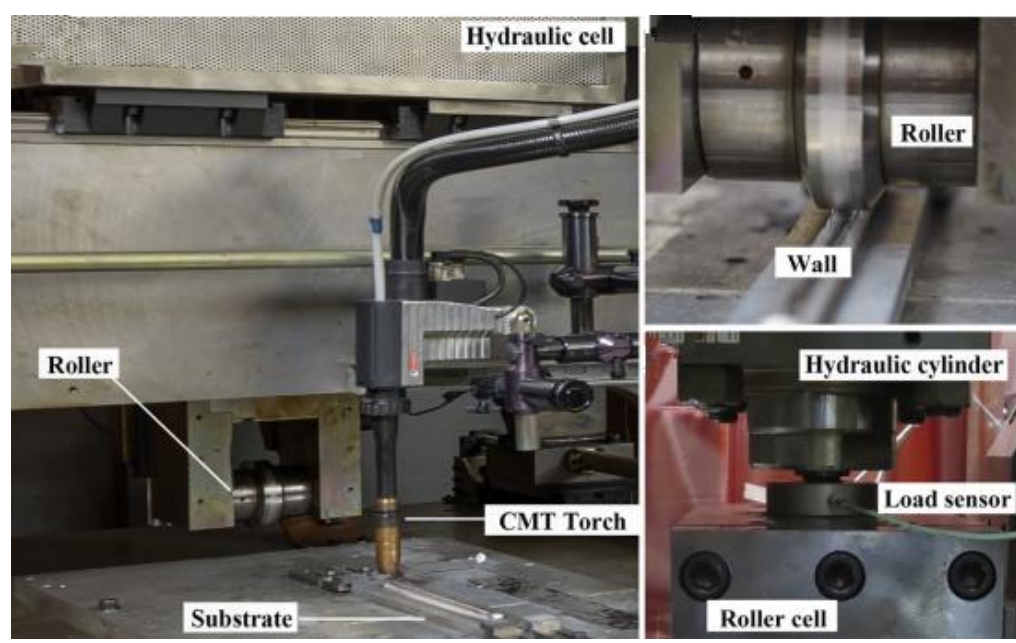

Fig. 4. Rolling and WAAM deposition setup [39] (Reproduced and adapted with permission from Ref. 39, Elsevier and Copyright Clearance Center grants permission)

Solving the problem of dimensional accuracy is significant for marketability of aluminum alloy WAAM. Jing [42] found the preheating temperature has an important influence on the dimensional accuracy, and the preheating can solve the problem of uneven formation using lowparameter welds. Guo et al. [43] used CMT-based WAAM to fabricate 5B06 deformed aluminum alloy, which proved that appropriate interlayer residence time can improve aluminum alloy surface oxidation and improve surface precision. Kazanas et al. [44] discussed the effect of the angle of the torch and substrate on the fabrication of thinwalled components in CMT-based WAAM aluminum alloy. Gomez et al. [45] used a Hall current sensor to record the current and voltage waveforms during the aluminum alloy CMT-based WAAM process, the experimental results proved that with the increasing of welding speed can maintain a constant layer width in the multi-layer thin walls due to heat accumulation.

The research on CMT-based WAAM of aluminum alloy has made some progress, but few studies on the stress distribution caused by different thermal dissipation conditions of aluminum alloy, which may become the focus of future research.

\subsection{GTAW-based}

Gas Tungsten Arc Weld(GTAW) utilizes an arc generated between the tungsten electrode and the weldment to melt base metal and filler wire. Compared with GMAWbased and CMT-based, GTAW-based has the advantages of stable arc combustion and lower deposition rate, which means GTAW-based can fabricate more smooth layer appearance [46-49]. In the GTAW-based WAAM, the heat input adjustment does not change the arc length, and the deposition rate can be independently controlled by adjusting the wire feed speed, which means the independent energy input and material input make the WAAM process easier to control than GMAW-based and CMT-based. [50] As early as 2001, Wang et al. [51] directly constructed 5356 aluminum alloy cylindrical parts by using variable polarity gas tungsten arc welding (VPGTAW), and studied the relationship between the geometric size of sedimentary layer and welding parameters. This opened the way for further research on GTAW-based WAAM.
In aspect of dimensional accuracy, Huang et al. [52] explored the process of 5A06 aluminum alloy fabricated by GTAW-based WAAM, studied the influence of preheating temperature and welding current on mechanical properties of the aluminum alloy components, established a substrate preheating temperature and peak current process specification. Geng et al. [47] conducted GTAW-based WAAM with 5A06 aluminum alloy wire, and studied influence of the wire feeding direction on dimensional accuracy and droplet transfer behavior. It proved that the offset of starting position in WAAM process will increase with the expansion of wire feeding angle and the distance from end of wire to melting pool surface. By calculating flight distance of the droplet in arc range, the compensation value of the positioning offset can offset the initial deviation.

In aspect of Properties, Zewu Qi et al [53] found that the microhardness, tensile properties and elongation of ER2024 and ER5087 aluminum alloys fabricated by GTAW-based WAAM presented an increasing trend with the increasing of solution treatment temperature. Wang et al. [54] studied the microstructure and properties of 4043 aluminum alloy fabricated by GTAW-based WAAM and proved that processing parameters including arc voltage (arc length), welding current, welding speed and wire feeding rate have a decisive impact on the dimensional accuracy, microstructure and mechanical properties of aluminum alloy components.

The content of elements largely determines the aluminum alloy properties [32]. GTAW-based has the characteristics of independent wire feeding, and can improve the alloying element content by double wire or multi wire feeding [55, 56]. Hao et al. [57] simultaneously filled SUS304 stainless steel wire and AA 4043 aluminum alloy wire by GTAW-based WAAM, and obtained a deposition sample with significantly higher hardness than original AA4303 aluminum alloy. Qi et al. [58] fabricated Al-Cu-Mg alloys by GTAW-based WAAM filling ER2319 (aluminum-copper) wire and ER5087 (aluminummagnesium) wire, the results shown that the microhardness presented an increasing trend with the increase of copper content. 


\subsection{PAW-based}

GTAW and GMAW are not bounded by other conditions except the magnetic field, the arc shape is relatively expanded, and the energy density as well as arc temperature are relatively low. Using nozzles with smaller aperture to restrain arc (as shown in Fig. 5), the crosssection area of arc column is limited, that is compressed intensely in the radial direction, thus forming plasma arc welding (PAW). Compared with TIG, PAW has the advantages of concentrated arc energy, better arc stiffness and higher arc stability, but the equipment is complex and gas consumption is large $[59,60]$.

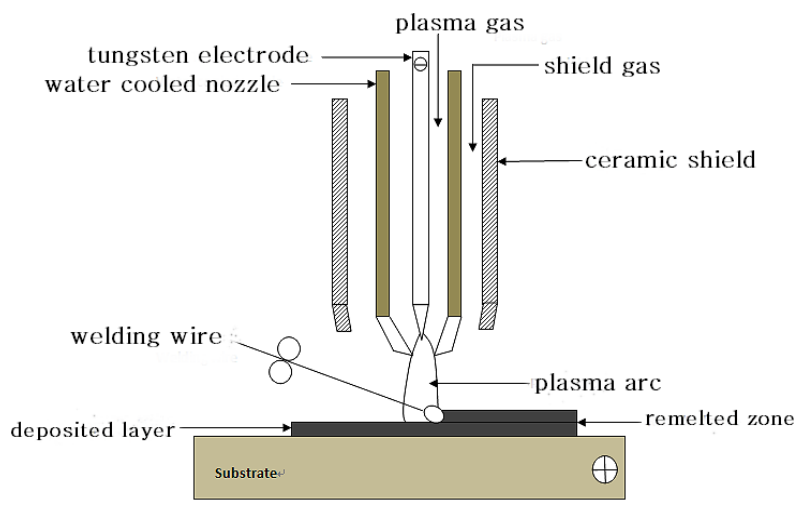

Fig. 5. Schematic diagram of plasma arc

At this stage, there has been a certain degree of progress in PAW-based WAAM for non-ferrous metals [61, 62]. Lin et al. [63] obtained Ti-6Al-4V thin wall by PAM-based WAAM process, and the average yield strength (YS) and ultimate tensile strength (UTS) reached 909MPa and $988 \mathrm{MPa}$, respectively. The mechanical properties of the samples are higher than the average level of forging. J. Xu [59] studied the effect of interlayer cooling on the microstructure and mechanical properties of Inconel 625 fabricated by PAW-based WAAM. It is proved that the grain is finer and uniform after interlayer cooling, and the mechanical properties are obviously improved.

However, the existing PAW-WAAM research at present is mainly in TI and Ni alloys, while there are few studies on aluminum alloys. The reason is that PAW is a high-energy beam (energy density is $105-106 \mathrm{~W} / \mathrm{cm} 2$, and the center temperature of the arc is $24000-50000 \mathrm{~K}$ ), while the melting point of aluminum alloy is low [64]. In the aluminum alloy WAAM process, the huge heat input will quickly reach the melting point of the formed part, resulting in uncontrollable manufacturing process and difficulties in predict components property. Therefore, the mandatory constraint on the components in the aluminum alloy WAAM process can also be one of the future research directions.

\section{DISCUSSION}

The WAAM process is different, but the manufacturing mechanism is basically similar. By analyzing the typical experiment $[21,23,30,32,47,51,52,54,58,65,66]$ of WAAM aluminum alloy, the general tendency of appearance and mechanical properties can be summarized. The microstructure of the components from bottom to top is basically a transition from columnar crystal to equiaxed crystal in the height direction (as shown in Fig. 6). Significant layered distribution characteristics were observed in the Components by GTAW-based WAAM, which were not evident in the aluminum alloy by GMAWbased WAAM (as shown in Fig. 7).

The reason is during the WAAM process, the microstructure of the formed part is determined by the temperature gradient around the bath and the cooling rate [6]. The bottom of the component is connected to the substrate, the temperature gradient is high, and the front of the solid-liquid interface is in the subcooled liquid phase region, where the nucleation is difficult, which is favorable for forming columnar crystals growing along the heat dissipation direction. Away from the middle area of the substrate, since the heat dissipation direction changes from three-dimensional to two-dimensional and each deposition is equivalent to heat treatment of the formed material.

When the molten pool solidifies, the temperature gradient at the solid-liquid interface is large and the liquid phase region in the supercooling state at the interface front is small, which leads to the nucleation is difficult, and the crystal grains are more likely to grow, thereby growing into columnar crystals. As the cooling progresses, the solidliquid phase interface moves forward, the temperature gradient gradually decreases, and the liquid-phase supercooling zone at the front of the solid-liquid interface becomes increasingly larger, so that the larger degree of subcooling provides sufficient power for nucleation.

A large number of crystal nuclei are formed in the liquid phase, and the crystal grains are mutually restricted to grow, thereby growing into fine equiaxed crystals, so that stratification characteristics appear, which resulting in the large heat input of GMAW-based will melt the upper surface deeply, structure tends to be uniform, and the stratification characteristics are not obvious.

The top tissue undergoes only one thermal action and the temperature gradient is small. The liquid phase in the longer distance of the solid-liquid phase interface is in a supercooling state, and the nucleus is simultaneously nucleated at the solid-liquid interface and the inside of the molten pool, Crystal nucleus will grow around, resulting in a large amount of dendritic or equiaxed crystal structure.

WAAM aluminum alloy is the as-cast structure, that means almost no anisotropy of tensile strength in horizontal and vertical directions (as shown in Table 2). The plasticity of the formed part depends on the intergranular deformation coordination ability. At the top and bottom, the grain growth direction is uniform, and the intergranular deformation coordination ability is stronger than the horizontal direction, the plasticity of the sample perpendicular to the substrate direction in this region is better than the sample parallel to the substrate. In the middle region, due to the stratification effect of the microstructure, the tissue growth has discontinuity, and there is a certain anisotropy in plasticity and toughness. Since the delamination effect of GMAWbased is not obvious, the plasticity and toughness of aluminum alloy different parts is isotropic. 

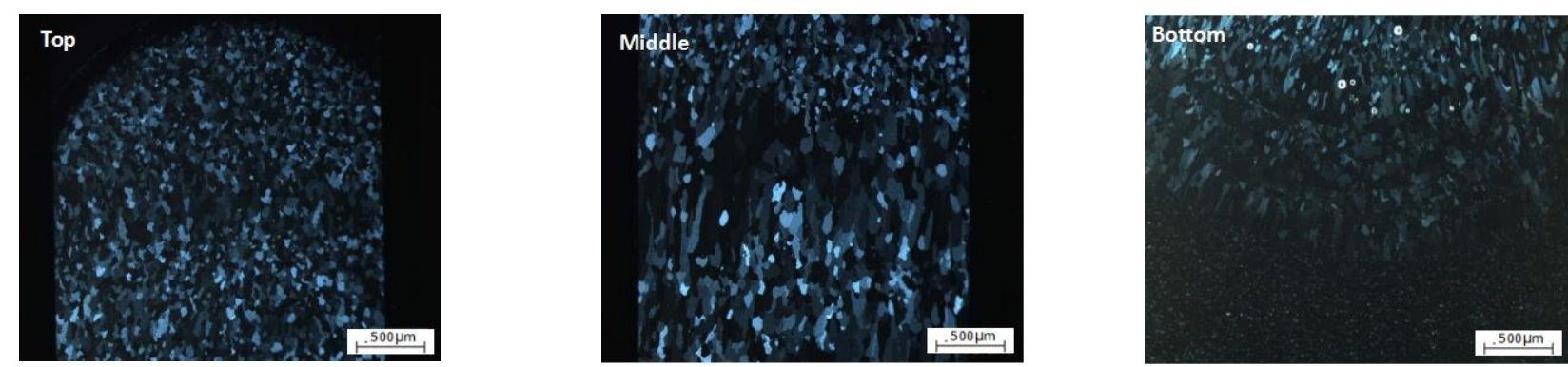

a

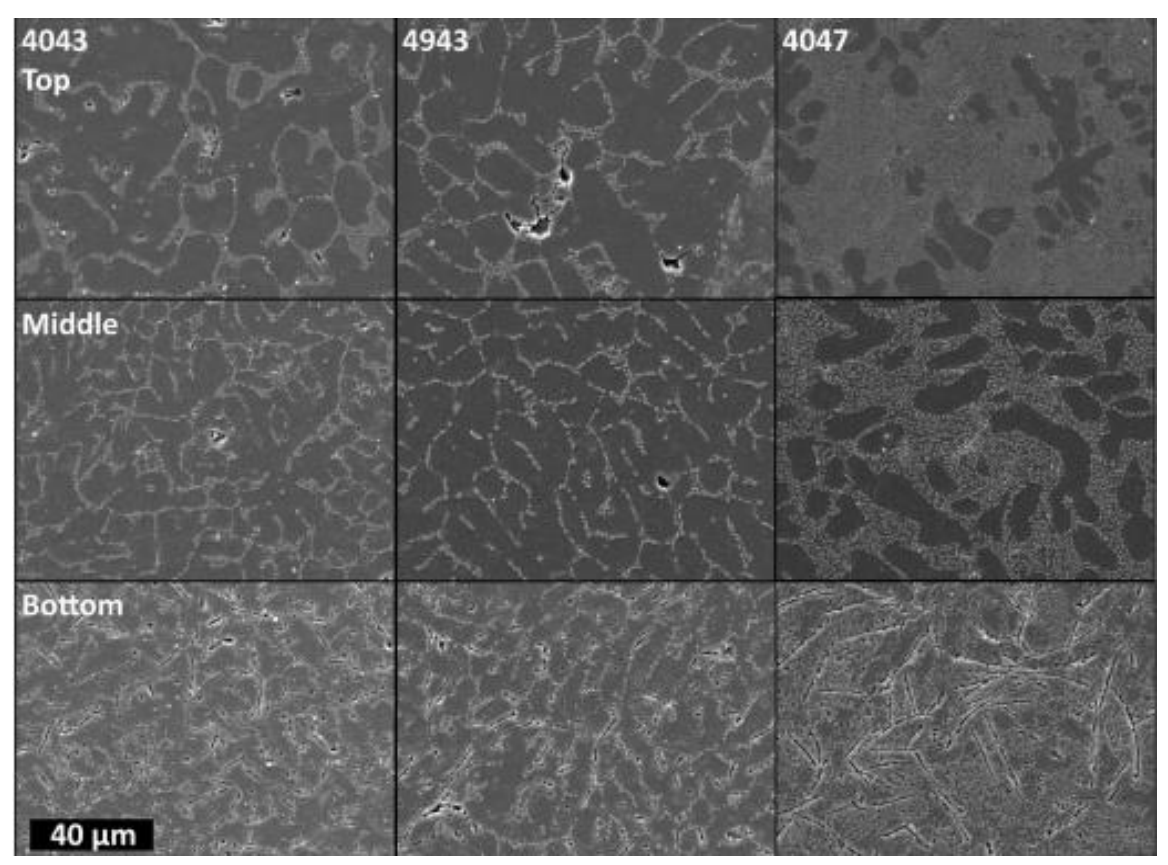

b

Fig. 6. Microstructure of aluminum alloy WAAM specimens in the bottom, top, and middle: a-microstructure of 5183 aluminum alloy by GTAW-based [65]; b- microstructure of 4000 series aluminum alloy by GMAW-based WAAM [21] (Reproduced and adapted with permission from Ref. 65 and Ref. 21, Harbin Institute of Technology grants permission Ref. 65. Elsevier and Copyright Clearance Center grants permission ref.21)

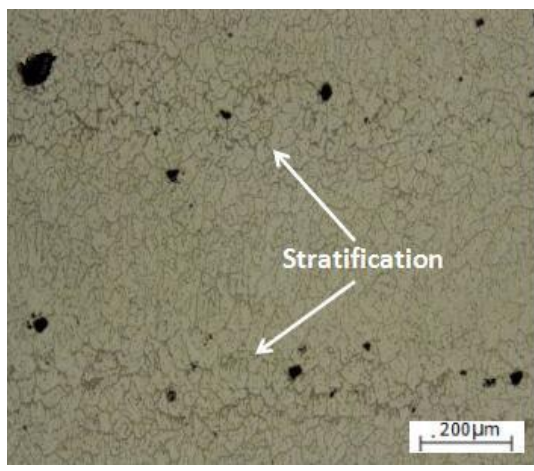

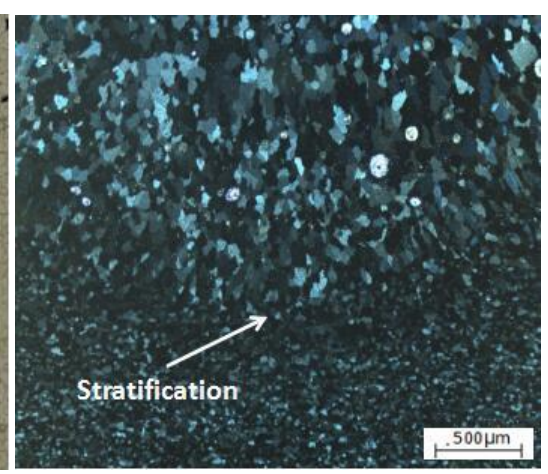

b

Fig. 7. Stratification of aluminum alloy by GTAW-based WAAM: a-2219 aluminum alloy [30]; b-5183 aluminum alloy [65] (Reproduced and adapted with permission from ref. 30 and ref. 65, Harbin Institute of Technology grants the two permissions)

\section{CONCLUSIONS AND PROSPECT}

Different WAAM processes have various characteristics, which will directly affect the appearance, microstructure, mechanical properties and processing efficiency of the aluminum alloy components. At present, the research on the aluminum alloys fabricated by GMAWbased is comprehensive. The difference in alloy content makes the mechanical properties of GMAW-based parts significantly different. It has been proved that optimizing the welding parameters, designing the path control scheme, using pulsed arc and laser induction can significantly improve the surface dimensional accuracy of the GMAWbased aluminum alloy. Pulsed arcs reduce porosity sensitivity and double pulsed arcs do not increase porosity in GMAW-based aluminum alloy. 
Table 2. Tensile properties of WAAM aluminum alloy

\begin{tabular}{|l|c|c|c|c|c|}
\hline \multicolumn{1}{|c|}{ Aluminum alloy } & WAAM process & $\begin{array}{c}\text { Horizontal tensile } \\
\text { strength, MPa }\end{array}$ & $\begin{array}{c}\text { Horizontal } \\
\text { elongation, } \%\end{array}$ & $\begin{array}{c}\text { Vertical tensile } \\
\text { strength, MPa }\end{array}$ & $\begin{array}{c}\text { Vertical elongation, } \\
\%\end{array}$ \\
\hline $2219[30]$ & GTAW & 239 & 10.32 & 234 & 9.86 \\
\hline $2319+5087[58]$ & GTAW & $280 \pm 5$ & 8.2 & $280 \pm 5$ & 6 \\
\hline 5 A06 [52] & GTAW & 295.13 & 36.0 & 293.37 & 35.0 \\
\hline $5183[65]$ & GTAW & 275.68 & 29.5 & 274.25 & 27.60 \\
\hline AA5183 [32] & GMAW & $296 \pm 5$ & $22.0 \pm 1$ & $293 \pm 5$ & $21.0 \pm 1$ \\
\hline \multirow{2}{*}{$5356[42]$} & CMT & 279.49 & 30 & 243.42 & 22.46 \\
\cline { 2 - 6 } & $\begin{array}{c}\text { CMT + Solution } \\
\text { treatment }\end{array}$ & 279.95 & 29.5 & 277.375 & 26.6 \\
\hline
\end{tabular}

Compared with the traditional GMAW-based, CMTbased has lower metal transition temperature and shorter gas escape time, which makes it easier to form porosity. Pulse arc, interlayer rolling and interlayer heat treatment can reduce the tendency of porosity in the process of CMTbased WAAM aluminum alloy. The overall heat treatment after forming will increase the porosity volume and quantity. Compared with GMAW-based and CMT-based, GTAW-based has the characteristics of independent wire feeding, the wire feeding speed can be adjusted to control the deposition rate and obtain a smoother aluminum alloy surface. GTAW-based can produce high-quality aluminum alloy parts with various trace elements by double or multi wire feeding. In addition to optimizing the GTAW process parameters, solution treatment and aging treatment have also been proved to improve the mechanical properties of GTAW-based aluminum alloys. The existing PAW-based research mainly exists in $\mathrm{TI}$ and $\mathrm{Ni}$ alloys.

The microstructure of WAAM aluminum alloys in different processes shows similarity. From bottom to top, large columnar crystals are transformed into small equiaxed crystals, so that the mechanical properties of horizontal and vertical samples (in terms of plasticity) show certain anisotropy. The grain size of WAAM aluminum alloys is determined by processing parameters and aluminum alloy elements. Suitable process parameters can control the heat input to optimize the grain size and macroscopic accuracy, but the change of parameters will directly affect the deposition rate of the aluminum alloy. In order to improve the process efficiency, in the case of increasing the heat input, the mandatory constraint on arc, droplet or molten pool in the WAAM process may become the key research direction in the future.

Aluminum alloy fabricated by WAAM still adopt the design configuration of traditional manufacturing process. Traditional structure does not take full advantage of the new design space provided by WAAM, which limits the structural properties of the aluminum alloy and even results in the performance being inferior to the traditional manufacturing process. Therefore, the topological optimization is one of the important topics in the practicability and marketability of WAAM aluminum alloy.

\section{REFERENCES}

1. Ford, S., Despeisse, M. Additive Manufacturing and Sustainability: An Exploratory Study of The Advantages and Challenges Journal of Cleaner Production 137 2016: pp. $1573-1587$.

https://doi.org/10.1016/j.jclepro.2016.04.150
2. Dave, M., Nitin, C. Additive Manufacturing Changing the Way Products are Made. DMG Mori:Chicago, America, 2014.

3. Tian, C.L., Chen, J.L., Dong, P., He, J.W., Wang, Y.J. Current State and Future Development of The Wire Arc Additive Manufacture Technology Abroad Aerospace Manufacturing Technology 2 2015: pp. 57-60.

4. Tabernero, I., Paskual, A., Álvarez, P., Alfredo, S. Study on Arc Welding Processes for High Deposition Rate Additive Manufacturing Procedia CIRP 68 2018: pp. 358-362. https://doi.org/10.1016/j.procir.2017.12.095

5. Heralic, A. Monitoring and Control of Robotized Laser Metal-Wire Deposition Chalmers University of Technology, Göteborg, Sweden 2012: pp. 1-64.

6. Derekar, K.S. A Review of Wire Arc Additive Manufacturing and Advances in Wire Arc Additive Manufacturing of Aluminium Materials Science and Technology 2018: pp. 895-916. https://doi.org/10.1080/02670836.2018.1455012

7. Williams, S.W., Martina, F., Addison, A.C., Ding, J., Pardal, G. Wire+Arc Additive Manufacturing Materials Science and Technology 7 2016: pp. $1-7$. https://doi.org/10.1179/1743284715Y.0000000073

8. Wu, B.T., Pan, Z.X., Ding, D.H., Cuiuri, D., Li, H.J., Xu, J., Norrish, J. A Review of the Wire Arc Additive Manufacturing of Metals: Properties, Defects and Quality Improvement Journal of Manufacturing Processes 35 2018: pp. $127-139$.

9. Wang, T.T., Zhang, Y.B., Wu, Z.H., Shi, C.W. Microstructure and Properties of Die Steel Fabricated by WAAM Using H13 Wire Vacuum 149 2018: pp. 185-189. https://doi.org/10.1016/j.vacuum.2017.12.034

10. Colegrove, P.A., Coules, H.E., Fairman, J., Martina, F., Kashoob, T., Mamash, H., Cozzolino, L. Microstructure and Residual Stress Improvement in Wire and Arc Additively Manufactured Parts Through High-Pressure Rolling Journal of Materials Processing Technology 213 (10) 2013: pp. $1782-1791$. https://doi.org/10.1016/j.jmatprotec.2013.04.012

11. Liu, F.C., He, L.H., Huang, C.P., Yang, C.G., Yu, X.B. Microstructure, Mechanical Properties and Processing Study of Arc Overlying Welding Rapid Forming of 316L Stainless Steel Journal of Nanchang Hangkong University: Natural Sciences 27 (4) 2013: pp. 1-5.

12. Wang, Z.T. Production, Market and Application of Aluminum Alloy Plate Light Alloy Fabrication Technology 33 (1) 2005: pp. 1-20.

13. Rashed, H., Rashid, A. Heat Treatment of Aluminum Alloys Comprehensive Materials Finishing 2017: pp. 337-371. https://doi.org/10.1016/b978-0-12-803581-8.09194-3

14. Liu, J.A., Liu, Y., Hang, P.Z., Liu, Z. G. Development Situation and Market Analysis of Aluminum Alloy Modern Extrusions Light Alloy Fabrication Technology 41 (3) 2013: pp. $13-21$. 
15. Dudek, P., Fajkiel, A., Tomasz, R. The Research on the Ablation Casting Technology for Aluminium Alloys Solid State Phenomena 223 2015: pp. 70-77. https://doi.org/10.4028/www.scientific.net/SSP.223.70

16. Miao, Q.Y., Liu, M.R., Zhao, K., Ma, G.Y., Wu, D.J. Research Progress on Technologies of Additive Manufacturing of Aluminum Alloys Laser \& Optoelectronics Progress 55 (1) 2018: pp. 1-9. https://doi.org/10.3788/LOP55.011405

17. Zhang, Y.M., Chen, Y.W., Li, P.J. Weld Deposition-Based Rapid Prototyping: a Preliminary Study Journal of Materials Processing Technology 135 (2) 2003: pp. 347-357. https://doi.org/10.1016/s0924-0136(02)00867-1

18. Mvola, B., Kah, P., Layus, P. Review of Current Waveform Control Effects on Weld Geometry in Gas Metal Arc Welding Process The International Journal of Advanced Manufacturing Technology 96 2018: pp. 4243-4265. https://doi.org/10.1007/s00170-018-1879-z

19. Ibrahim, I.A., Mohamat, S.A., Amir, A., Ghalib, A. The Effect of Gas Metal Arc Welding (GMAW) Processes on Different Welding Parameters Procedia Engineering 41 2012: pp. $1502-1506$.

https://doi.org/10.1016/j.proeng.2012.07.342

20. Jiang, B., Yi, D.Q., Yi, X.O., Zheng, F., Wang, H.S., Wang, B., Liu, H.Q., Hu, Z. Effect of Trace Amounts of Added Sc on Microstructure and Mechanical Properties of 2055 Aluminum Alloy Materials Characterization 141 2018: pp. $248-259$.

https://doi.org/10.1016/j.matchar.2018.04.041

21. Haselhuhn, A.S., Buhr, M.W., Wijnen, B., Sanders, P.G., Pearce, J.M. Structure-Property Relationships of Common Aluminum Weld Alloys Utilized as Feedstock for GMAWBased 3-D Metal Printing Materials Science and Engineering: A 673 2016: pp. 511-523. https://doi.org/10.1016/j.msea.2016.07.099

22. Ogino, Y., Asai, S., Hirata, Y. Numerical Simulation of WAAM Process by a GMAW Weld Pool Model Welding in the World 62 (2) 2018: pp. 1-9. https://doi.org/10.1007/s40194-018-0556-Z

23. Zhao, X.X.,Sun, C., Ye, F.X., Luo, Z. Effect of MIG Welding Parameters and Trajectory on Layer Geometry Shape in Additive Manufacturing Welding \& Joining 4 2016: pp. $33-36$

24. Li, F., Chen, S., Wu, Z., Yan, Z.H. Adaptive Process Control of Wire and Arc Additive Manufacturing for Fabricating Complex-Shaped Components The International Journal of Advanced Manufacturing Technology 96 2018: pp. $871-879$. https://doi.org/10.1007/s00170-018-1590-0

25. Luo, Y., Li, J.L., Xu, J., Liang, Z., Han, J.T., Zhang, C.Y. Influence of Pulsed Arc on The Metal Droplet Deposited by Projected Transfer Mode in Wire-Arc Additive Manufacturing Journal of Materials Processing Technology 259 2018: pp. 353-360.

https://doi.org/10.1016/j.jmatprotec.2018.04.047

26. Sun, C.S., Zhang, Z.D., Liu, L.M. Microstructure and Mechanical Properties of 5356 Aluminum Alloy Thin-Walled Parts Fabricated by Laser Induced MIG Arc Additive Welding Technology 46 (5) 2017: pp. 47-50.

27. Mayer, H., Papakyriacou, M., Zettl, B., Stanzi, S.E. Influence of Porosity on The Fatigue Limit of Die Cast Magnesium and Aluminium Alloys International Journal of Fatigue 25 (3) 2003: pp. 245-256. https://doi.org/10.1016/s0142-1123(02)00054-3

28. Hang, S., Bhuiyan, S., Toda, H., Uesugi, K., Takewchi, A., Watanabe, Y. Influence of Intermetallic Particles on The Initiation and Growth Behavior of Hydrogen Micropores
During High-Temperature Exposure in Al-Zn-Mg-Cu Aluminum Alloys Scripta Materialia 135 2017: pp. 19-23. https://doi.org/10.1016/j.scriptamat.2017.03.020

29. Liang, Z., Li, J.L., Luo, Y., Han, J,T., Zhang, C.Y., Xu, J., Chen, D. Characteristics of Metal Droplet Transfer in WireArc Additive Manufacturing of Aluminum Alloy The International Journal of Advanced Manufacturing Technology 99 2018: pp. 1521-1530. https://doi.org/10.1007/s00170-018-2604-7

30. Wang, J.H. Research on Shaped Metal Deposition of 2219 Aluminum Alloy by AC-TIG Welding Harbin Institute of Technology: Harbin, China, 2015.

31. Silva, C., Scotti, A. The Influence of Double Pulse on Porosity Formation in Aluminum GMAW Journal of Materials Processing Technology 171 (3) 2006: pp. $366-372$. https://doi.org/10.1016/j.jmatprotec.2005.07.008

32. Horgar, A., Fostervoll, H., Nyhus, B., Ren, X., Eriksson, M., Akselsen, O.M. Additive Manufacturing Using WAAM with AA5183 Wire Journal of Materials Processing Technology 259 2018: pp. 68-74. https://doi.org/10.1016/j.jmatprotec.2018.04.014

33. Hao, X., Huang, Y.D., Chen, W. Research Status of The Aluminium Alloy Arc Additive Manufacturing Technology Based on the CMT Journal of Netshape Forming Engineering 10 (5) 2018: pp. 88-94.

34. Ahsan, M.R., Cheepu, M., Kim, T.H., Jeong, C.Y., Park, Y.D. Mechanisms of Weld Pool Flow and Slag Formation Location in Cold Metal Transfer (CMT) Gas Metal Arc Welding (GMAW) Welding in the World 61 2017: pp. 1287. https://doi.org/10.1007/s40194-017-0489-y

35. Zhang, H.T., Song, J.Q. Microstructural Evolution of Aluminum/Magnesium Lap Joints Welded Using MIG Process with Zinc Foil as an Interlayer Materials Letters 65 (21) 2011: pp. $3292-3294$. https://doi.org/10.1016/j.matlet.2011.05.080

36. Cao, R., Wen, B.F., Chen, J.H., Wang, P.C. Cold Metal Transfer Joining of Magnesium AZ31B- to-Aluminum A6061-T6 Materials Science and Engineering: A (Structural Materials: Properties, Microstructure and Processing) 560 2013: pp. $256-266$. https://doi.org/10.1016/j.msea.2012.09.065

37. Cong, B., Ding, J., Williams, S. Effect of Arc Mode in Cold Metal Transfer Process on Porosity of Additively Manufactured Al-6.3\% Cu Alloy The International Journal of Advanced Manufacturing Technology 76 (9) 2015: pp. $1593-1606$. https://doi.org/10.1007/s00170-014-6346-x

38. Cong, B.Q., Ding, J.L. Influence of CMT Process on Porosity of Wire Arc Additive Manufactured Al-Cu Alloy Rare Metal Materials and Engineering 43 (12) 2014: pp. 3149-3153.

39. Gu, J.L., Ding, J.L., Williams, S.W., Gu, H.M., Ma, P.H., Zhai, Y.C. The Effect of Inter-Layer Cold Working and PostDeposition Heat Treatment on Porosity in Additively Manufactured Aluminum Alloys Journal of Materials Processing Technology 230 2016: pp. 26-34. https://doi.org/10.1016/j.jmatprotec.2015.11.006

40. Gu, J.L., Ding, J.L., Williams, S.W., Bai, J., Zhai, Y.C., Ma, P.H.The Strengthening Effect of Inter-layer Cold Working and Post-deposition Heat Treatment on the Additively Manufactured Al-6.3Cu Alloy Materials Science and Engineering $A \quad 651$ 2015: pp. 18-26. https://doi.org/10.1016/j.msea.2015.10.101

41. Bai, J., Ding, H.L., Gu, J.L. Porosity Evolution in 
Additively Manufactured Aluminium Alloy During High Temperature Exposure IOP Conference Series: Materials Science and Engineering 167 2017: pp. 1-4. https://doi.org/10.1088/1757-899X/167/1/012045

42. Jiang, Y.L. Research on The Rapid Prototyping Technology and Forming Proming Process of Aluminum Alloy Based on The CMT Harbin Institute of Technology: Harbin, China, 2013.

43. Sun, H.Y., Cong, B.Q., Su, Y., Qi, B.J., Qi, Z.W., Wang, Q. Geometry, Microstructure and Properties of Wire+Arc Additive Manufacturing Al-6.3Cu Alloy Deposits Aeronautical Manufacturing Technology 2017: pp. $72-76$

44. Kazanas, P., Deherkar, P., Almeida, P., Lockett, H., Williams, S. Fabrication of Geometrical Features Using Wire and Arc Additive Manufacture Journal of Engineering Manufacture 226 (6) 2012: pp. 1042-1051.

45. Gomez, O.A., Corona, G.L., Deschaux, B.F., Mezray, B., Rouquette, S. Effect of Process Parameters on The Quality of Aluminium Alloy A15Si Deposits in Wire and Arc Additive Manufacturing Using A Cold Metal Transfer Process Science and Technology of Welding and Joining 2017: pp. 1-17. https://doi.org/10.1080/13621718.2017.1388995

46. Lu, F., Yao, S., Lou, S.N., Li, Y.B. Modeling and Finite Element Analysis on GTAW Arc and Aeld Pool Computational Materials Science $29(3)$ 2004: pp. $371-378$.

https://doi.org/10.1016/j.commatsci.2003.10.009

47. Geng, H., Li, J., Xiong, J., Lin, X., Zhang, F.S. Optimization of Wire Feed for GTAW Based Additive Manufacturing Journal of Materials Processing Technology 243 2017: pp. 40-47.

https://doi.org/10.1016/j.jmatprotec.2016.11.027

48. Pujari, K.S., Patil, D.D. A Review on GTAW Technique for High Strength Aluminium Alloys (AA 7xxx Series) International Journal of Engineering Research \& Technology 2(8) 2013: pp. $1-15$.

49. Lin, S., Song, J., Guangchao, M.A., Yang, C.L. Dissimilar Metals TIG Welding-Brazing of Aluminum Alloy to Galvanized Steel Frontiers of Materials Science 3(1) 2009: pp. $78-83$. https://doi.org/10.1007/s11706-009-0007-2

50. Geng, H., Li, J., Xiong, J., Lin, X., Zhang, F.S. Optimization of Wire Feed for GTAW Based Additive Manufacturing Journal of Materials Processing Technology 243 2017: pp. 40-47. https://doi.org/10.1016/j.jmatprotec.2016.11.027

51. Wang, H., Kovacevic, R. Rapid Prototyping Based on Variable Polarity Gas Tungsten Arc Welding for A 5356 Aluminium Alloy Proceedings of the Institution of Mechanical Engineers Part B Journal of Engineering Manufacture 215 (11) 2001: pp. 1519-1527.

52. Huang, D., Zhu, Z.H., Geng, H.B., Xiong, Z.T. TIG Wire and Arc Additive Manufacturing of 5A06 Aluminum Alloy Journal of Materials Engineering 45(3) 2017: pp. 66-72. https://doi.org/10.11868/j.issn.1001-4381.2015.000552

53. Qi, Z.W., Cong, B.Q., Qi, B.J., Zhao, G., Ding, J.L. Properties of Wire+Arc Additively Manufactured 2024 Aluminum Alloy with Different Solution Treatment Temperature Materials Letters 230 2018: pp. 275-278. https:// doi.org/10.1016/j.matlet.2018.07.144

54. Wang, H.J., Jiang, W.H., Ouyang, J.H., Kovacevic, R. Rapid Prototyping of 4043 Al-Alloy Parts by VP-GTAW
Journal of Materials Processing Technology

2004: pp. $93-102$.

https://doi.org/10.1016/j.jmatprotec.2004.01.058

55. Shen, C., Pan, Z.X., Cuiuri, D., Roberts, T., Li, H.J. Fabrication of Fe-FeAl Functionally Graded Material Using the Wire-Arc Additive Manufacturing Process Metallurgical and Materials Transactions B 47 (1) 2016: pp. $763-772$. https://doi.org/10.1007/s11663-015-0509-5

56. Ma, Y., Cuiuri, D., Hoye, N., Li, H.J. Effects of Wire Feed Conditions on Insitu Alloying and Additive Layer Manufacturing of Titanium Aluminium Using Gas Tungsten arc Welding Journal of Materials Research 29 (17) 2014: pp. 2066-2071. https://doi.org/10.1557/jmr.2014.203

57. Huang, Z.Z, San, S.A., Yang, C.C. Formation of SUS304/Aluminium Alloys Using Wire and Arc Additive Manufacturing Metals 8 2018: pp. 595-607.

58. Qi, Z.W., Cong, B.Q., Qi, B.J., Sun, H.Y., Zhao, G., Ding, J.L. Microstructure and Mechanical Properties of Double-Wire + Arc Additively Manufactured Al-Cu-Mg Alloys Journal of Materials Processing Technology 255 2018: pp. 347-353 https://doi.org/10.1016/j.jmatprotec.2017.12.019

59. Martina, F., Mehnen, J., Williams, S.W., Colegrave, P., Wang, F. Investigation of The Benefits of Plasma Deposition for The Additive Layer Manufacture of Ti-6Al-4V Journal of Materials Processing Technology 212 2012: pp. $1377-1386$. https://doi.org/10.1016/j.jmatprotec.2012.02.002.

60. Gao, J.Q., Wu, C.S., Liu, X.Z., Xia, D. X. Vision-Based Weld Seam Tracking in Gas Metal Arc Welding Frontiers of Materials Science in China 1 (3) 2007: pp. 268-273. https://doi.org/10.1007/s11706-007-0048-3.

61. Bai, X.W., Colegrove, P., Ding, J.L., Zhou, X.M., Diao, C.L., Bridgeman, P., Jan, R., Zhang, H.O., Williams, S. Numerical Analysis of Heat Transfer and Fluid Flow in Multilayer Deposition of PAW-Based Wire and Arc Additive Manufacturing International Journal of Heat \& Mass Transfer 124 2018: pp. 504-516.

62. Font, C.T., Diao, C.L., Ding, J.L., Williams, S. A Passive Imaging System for Geometry Measurement for The Plasma Arc Welding Process IEEE Transactions on Industrial Electronics 64 (9) 2017: pp. $7201-7209$. https://doi.org/10.1109/TIE.2017.2686349

63. Xu, F.J., Lv, Y.H., Xu, B.S.,Liu, Y.X., Shu, F.Y., He, P. Effect of Deposition Strategy on The Microstructure and Mechanical Properties of Inconel 625 Superalloy Fabricated by Pulsed Plasma Arc Deposition Materials and Design 45 2013: pp. 446-455. https://doi.org/10.1016/j.jmst.2013.02.010

64. Li, J., Yang, J.G., Li, H.L., Yan, D.J., Fang, H.Y. Numerical Simulation on Bucking Distortion of Aluminum Alloy Thin-Plate Weldment Frontiers of Materials Science in China 3 (1) 2009: pp. 84-88. https://doi.org/10.1007/s11706-009-0006-3

65. Shi, J.X. Nunerical Simulation and Microstructure of 5183 Aluminum by Additive Manufacturing of TIG, Harbin Institute of Technology: Harbin, China 2016: pp. 1-69.

66. Shen, C., Pan, Z., Cuiuri, D., Roberts, J., Li, H.J. Fabrication of Fe-FeAl Functionally Graded Material Using the Wire-Arc Additive Manufacturing Process Metallurgical and Materials Transactions B 47 (1) 2016: pp. $763-772$. https://doi.org/10.1007/s11663-015-0509-5 